\title{
SEM imaging and XPS characterization of doped PVDF fibers
}

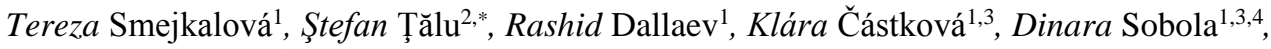 \\ and Anton Nazarov ${ }^{5}$ \\ ${ }^{1}$ Brno University of Technology, Technická 2848/8, 61600 Brno, Czech Republic \\ ${ }^{2}$ The Technical University of Cluj-Napoca, Constantin Daicoviciu Street, no. 15, Cluj-Napoca, \\ 400020, Cluj county, Romania \\ ${ }^{3}$ Central European Institute of Technology BUT, Purkyňova 123, 61200 Brno, Czech Republic \\ ${ }^{4}$ Dagestan State University, Makhachkala, St. M. Gadjieva 43-a, Dagestan Republic 367015, Russia \\ ${ }^{5}$ Ural State University of Economics, Russian Federation
}

\begin{abstract}
Polyvinylidene fluoride (PVDF) is one of the most promising electroactive polymers; it exhibits excellent electroactive behaviours, good biocompatibility, excellent chemical resistance, and thermal stability, rendering it an attractive material for biomedical, electronic, environmental and energy harvesting applications. This work aims to further improve its properties by the inclusion of powders of piezoactive materials. Polyvinylidene fluoride was formed by electrospinning into fibres with a thickness of 1.5-0.3 $\mu \mathrm{m}$ and then examined in a scanning electron microscope. The work offers a description of the current procedure in the preparation of samples and their modification for examination in a scanning electron microscope, characterizes the individual components of doped fibres and deals with specific instruments used for various analytical methods. The work contains a theoretical introduction to the analytical methods to which the samples will be further subjected, such as energy dispersive X-ray spectroscopy (EDX), X-ray photoelectron spectroscopy (XPS). The obtained excellent properties of doped PVDF could be used in the design of sensors.
\end{abstract}

\section{Introduction}

Nanotechniques can be applied in many different applications across industries, including medicine, space travel, energy, or environment. Unlike most scientific disciplines, it does not have a single focus, and its discoveries can be used in many other areas of manufacturing, science, and technology (Țălu, 2015; Țălu et al., 2018; Mwema et al., 2020; Sobola et al., 2020). Principally, the modification of materials provides additional features and aptitudes while maintaining the fundamental characteristics of the materials (Dallaeva et al., 2014; Stach et al., 2015; Ramazanov et al., 2015; Dallaev et al., 2019). Creating those complex structures can only be controlled if we understand the nature of the

\footnotetext{
* Corresponding author: stefan ta@yahoo.com
} 
processes that regulate them during the synthesis of the conducting polymers, and the extent to which the application of electrical stimulus changes these properties (Wallace et al., 2008). These advanced processes and their outcomes are the focus of this work.

It is possible to create polymers in wide range of electrical conductivity with a diverse range of properties. A wide variety of synthesis and processing methods allow the production of materials whose electrical properties include different capacitance, or dielectric strength. Furthermore, the act of stretching a macromolecular system into a fibre orients the polymer chains and increases intermolecular interactions; thus, while the diameter of a fibre is much reduced by the drawing process, this is offset by the increased modulus of the fibres which can produce some of the strongest materials known (Geoffrey, 2015).

The electroactive material used in this thesis is Polyvinylidene fluoride (PVDF), a material with excellent piezoelectricity and good biocompatibility.

PVDF exhibits five crystalline polymorphs including nonpolar $\alpha$ - and $\varepsilon$-phases, and polar $\beta$-, $\gamma$ - and $\delta$-phases depending on the crystallisation and processing conditions. Polar $\beta$-phase, as explained by Lim et al. (2015), has all of its dipoles aligned in the same direction normal to the chain axis. Its unit cell consists of two all-trans chains packed with their dipoles pointing in the same direction. The molecular dipoles in the $\beta$-phase are thus entirely aligned in one direction; this crystal form can consequently generate the largest spontaneous polarisation and exhibits strong ferroelectric and piezoelectric properties.

These unique $\beta$-phase properties of PVDF make it useful in a wide range of applications, including actuators, biosensor, energy harvesting materials, audio devices, transducers, and non-volatile memories (Lim et al., 2015). Additionally, by doping of PVDF by ceramic particles, it is possible to obtain high dielectric constant. Polymers possess good processability, mechanical flexibility and low cost but have a very small value of dielectric constant to be useful as capacitors. Therefore, polymer-ceramic composites can be a good choice to achieve miniaturisation of energy storage devices by combining the merits of polymers and ceramics (Anshuman et al., 2014).

Piezoelectric materials are unique materials which generate an electric charge in response to applied stress or slight mechanical deformation, thus eliminating the need for external power sources for electrical stimulation. Typical piezoelectric materials include barium titanate, lead titanate and lead zirconate titanate ceramics as well as electroactive polymers such as polyvinylidene fluoride (PVDF) (Martins et al., 2014). Piezoelectric polymers exhibit several distinct advantages over piezoceramics including nontoxic, excellent flexibility, light weight and ease of fabrication (Kaspar et al., 2020).

There are mainly two kinds of piezoelectric polymer materials: the polymer materials which intrinsically have the piezoelectric effect, and electret - materials, that can preserve the induced charges for a longer period of time. Polymer materials with piezoelectric effect are mainly PVDF and its copolymers, and their properties are discussed in next chapter. Electrets can not only be used in the fabrication of piezoelectric generators, but also triboelectric generators based on electrostatic induction effect (Huisheng et al., 2017).

They are prepared by being heated and simultaneously exposed to an electric field. Due to this process, many dipoles in the material become oriented in a preferred direction. After the heating, the material is "frozen" and can keep the position of its electric dipoles for a long period of time (Buchtela, 2003; Ramazanov et al., 2020).

The $\beta$-PVDF-phase exhibits excellent ferroelectric and piezoelectric properties - PVDF and its copolymers can generate electrical charges on its surface upon mechanical or electrical stimulation. The $\beta$-phase can be promoted in PVDF by either mechanical drawing, annealing, electrical poling, or nanoparticle additions (Li et al. 2013).

Aided by recent advances in nanotechnology, a wide range of nanomaterials can be synthesized for biomedical and industrial applications. In particular, clay nanoplatelets, 
carbon nanotubes, graphene/graphene oxide and silica nanoparticles have been reported to be very effective to induce $\beta$-phase in PVDF (Haddadi et al., 2018).

PVDF exhibits excellent electroactive behaviours, good biocompatibility, excellent chemical resistance, and thermal stability, rendering it an attractive material for biomedical, electronic, environmental and energy harvesting applications (Liu et al., 2018).

The polymorphs of PVDF and its copolymers are typically identified using X-ray diffraction (XRD), Fourier transform infrared spectroscopy (FTIR), and differential scanning calorimetry (DSC). Polar $\beta$-phase can be induced in the PVDF fibres as a result of the polymer jet stretching and electrical poling during electrospinning. The main drawbacks of the electrospinning process for making piezoelectric PVDF-based scaffolds are their small pore sizes and the use of highly toxic organic solvents. Accordingly, modified electrospinning methods such as melt-electrospinning and near-field electrospinning have been explored by the researchers to tackle this issue ( $\mathrm{Li}$ et al., 2019).

\section{Experimental detail}

\subsection{Description of the used dopants}

\subsubsection{Titanium dioxide}

Titanium dioxide $\left(\mathrm{TiO}_{2}\right)$ is a non-toxic, non-reactive and polymorphous material which may be present in the rutile, anatase and brookite phases. The anatase phase, most commonly used, shows tetragonal crystalline structure, and is formed at low temperatures, around $450{ }^{\circ} \mathrm{C}$ (You et al., 2017).

The excellent performance of $\mathrm{TiO}_{2}$ in heterogeneous photocatalysis processes is due it is insoluble in water, non-toxic, photostable and chemically stable over a wide range of $\mathrm{pH}$ (Javed et al., 2019).

$\mathrm{TiO}_{2}$ occurs in many silicates in nature, accounting for over $1 \%$ of the earth's crust. Thus, it is manufactured using a variety of materials and processes (applications for $\mathrm{TiO}_{2}$ include paints, pharmaceuticals, paper, plastics, sunscreen and food) (Har, and Kumar, 2014).

\subsubsection{Zinc oxide}

Zinc oxide $(\mathrm{ZnO})$ is one of the most interesting polyfunctional materials and in recent years has received increased attention from the scientific community (Gorokhova et al., 2011). The enhanced interest is connected with the wide application of $\mathrm{ZnO}$ in electronic and photonic devices and systems, including UV LEDs and photodetectors, lasers in the blue and UV regions, and nanostructures of numerous forms and purposes (Look, 2006).

The demand for $\mathrm{ZnO}$ is determined by a unique collection of properties that gives it an advantage over other materials in a number of parameters (Özgür et al., 2005). ZnO is a direct-band semiconductor with a band gap of $3.37 \mathrm{eV}$ at $300 \mathrm{~K}$ and large exciton-binding energy (about $60 \mathrm{meV}$ ), which makes the exciton stable at room temperature. Various devices in which $\mathrm{ZnO}$ is used can operate at high values of background radiation, for example, in space, since this material is characterized by high radiation stability (Gorokhova et al., 2011).

\subsubsection{Barium titanate}


Barium titanate (BT) is a lead free and environmentally friendly ferroelectric material. It is chemically and mechanically stable and it exhibits ferroelectric properties at and above room temperature (RT) and it can be easily prepared and used in the form of ceramic polycrystalline samples (Stojanovic et al., 2004).

BT ceramics are widely used in the fabrication of multilayer ceramic capacitors (MLC) and nonvolatile memory devices because of their high dielectric constant and low dissipation factor at RT. It is also known that the purity of the starting precursors affects the processing temperatures and hence the material properties (Patel et al., 2011; Uchino, 2000).

\subsubsection{Barium calcium zirconate titanate}

Barium calcium zirconate titanate $\left((\mathrm{Ba}, \mathrm{Ca})(\mathrm{Zr}, \mathrm{Ti}) \mathrm{O}_{3}, \mathrm{BCZT}\right)$ is a lead-free piezoelectric material with excellent dielectric, ferroelectric and piezoelectric properties and large tunability (Parjansri et al., 2019). It is applicable in a variety of applications, such as multilayer ceramic capacitors (MLCC), piezoelectric actuators, and positive temperature coefficient resistors (PTCR), due to its excellent dielectric, ferroelectric and piezoelectric properties.

Moreover, its properties can be controlled by varying the $\mathrm{Ba} / \mathrm{Ca}$ and $\mathrm{Zr} / \mathrm{Ti}$ compositions. However, this material requires a high sintering temperature $\left(>1450{ }^{\circ} \mathrm{C}\right)$ which does not agree with the industrial's requirements. In order to decrease the sintering temperature, it is necessary to produce powders with fine particle sizes and homogeneous distribution (Frattini et al., 2012).

\subsubsection{Potassiumsodium niobate}

In recent years, researchers have been interested in developing lead-free piezoelectric materials as alternatives to lead-based materials, such as $\left(\mathrm{K}_{0.5} \mathrm{Na}_{0.5}\right) \mathrm{NbO}_{3}(\mathrm{KNN})$, $\left(\mathrm{Na}_{0.5} \mathrm{Bi}_{0.5}\right) \mathrm{TiO}_{3} \quad(\mathrm{NBT}), \quad\left(\mathrm{BaZr}_{\mathrm{x}} \mathrm{Ti}_{(1-\mathrm{x})} \mathrm{O}_{3} \quad(\mathrm{BZT})\right.$ and $\mathrm{Ba}_{(1-\mathrm{x})} \mathrm{Ca}_{\mathrm{x}} \mathrm{TiO}_{3} \quad$ (BCT). Potassiumsodium niobate $\left[(\mathrm{K}, \mathrm{Na}) \mathrm{NbO}_{3}, \mathrm{KNN}\right]$ have been thought as one of the most promising lead-free piezoelectric candidate because of relatively good comprehensive performance (Jiagang, 2018).

Alkaline niobate ceramics $(\mathrm{K}, \mathrm{Na}) \mathrm{NbO}_{3}$ exhibit particularly high piezoelectric characteristics and a relatively high Curie temperature $\left(\mathrm{T}_{\mathrm{c}}\right)$ (Kazushige, 2016). The roomtemperature piezoelectric properties in KNN-based ceramics can be largely improved by proper chemical modifications, which are actually due to the tetragonal-orthorhombic PPT point (TO-T) shifting downward from around $200{ }^{\circ} \mathrm{C}$ toward room temperature, namely PPT effect (Li et al., 2013).

\subsection{Materials and methods}

SEM can image all kinds of samples: ceramics, metals and alloys, semiconductors, polymers, biological samples, and much more. However, the surface of the non-metal samples acts as an electron trap. The resulting accumulation of electrons on the surface is called "charging" and creates white empty regions on the resulting image and influence the image information. When a metal coating is used, the conductive surface acts as a channel that allows the charging electrons to be removed from the material (Luyk, 2019).

Polyvinylidene fluoride, as a non-metal, must be covered with a conductive material to allow observation in SEM. Moreover, creating a conductive layer of metal on the sample inhibits charging, reduces thermal damage, and improves the secondary electron signal 
required for topographic examination in the SEM (Höflinger, 2013). In this case, fine carbon and gold layers were used for analysed samples.

The coating technique used depends on the resolution and application. Historically, the most frequently used coating material has been gold because of its high conductivity and relatively small grain size, which makes it ideal for high-resolution imaging. The atoms of gold are sputtered from a ring-shaped target - when a high potential difference is established between electrodes, an electrical discharge passes between them. The cathode electrode is then bombarded by positive ions of a residual gas such as argon (Fourie, 1982).

Energy-dispersive X-ray (EDX) analysis was done using Tescan Lyra 3 which is a dual beam system combining a high-resolution FE-SEM column with a versatile highperformance $\mathrm{Ga}$ ion source FIB, that is able to generate an image of the surface or to modify it with nanometric resolution (usually better than $10 \mathrm{~nm}$ ) (http://nano.ceitec.cz/ focused-ion-beam-scanning-electron-microscope-tescan-lyra3lyra/).

X-ray photoelectron spectroscopy was carried out by AXIS SupraTM X-ray photoelectron spectrometer (Kratos Analytical). It helped to define type of chemical state of the samples elements (Amit and Susmita, 2013, Cástková, et.al., 2020, Knápek, et.al., 2018).

\section{Experimental results}

\subsection{Scanning electron microscopy and energy-dispersive $X$-ray analysis}

Scanning electron microscopy of PVDF modified with various dopants are given in Figure 1.

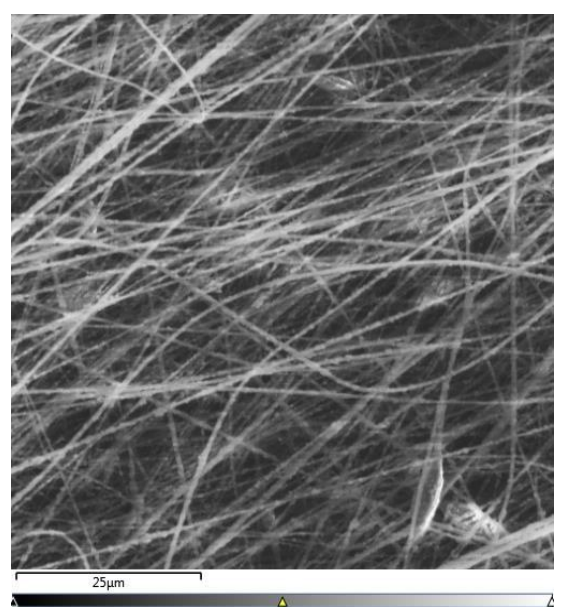

a) 


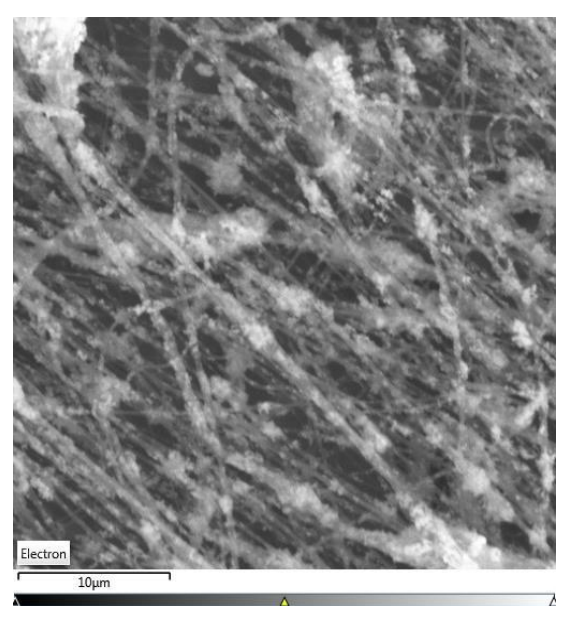

b)

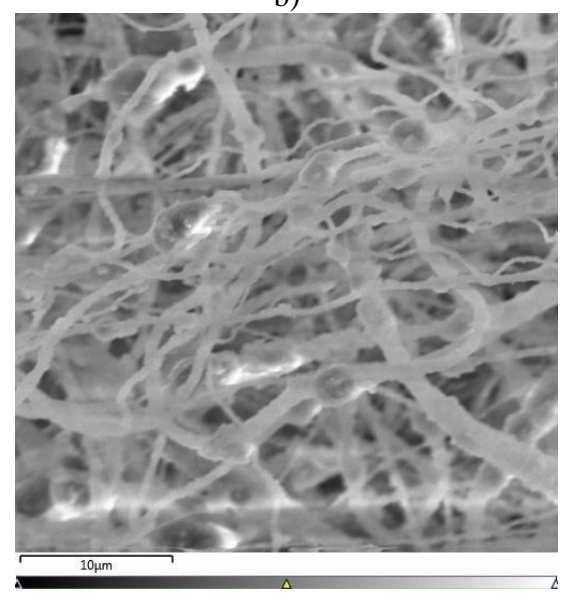

c)

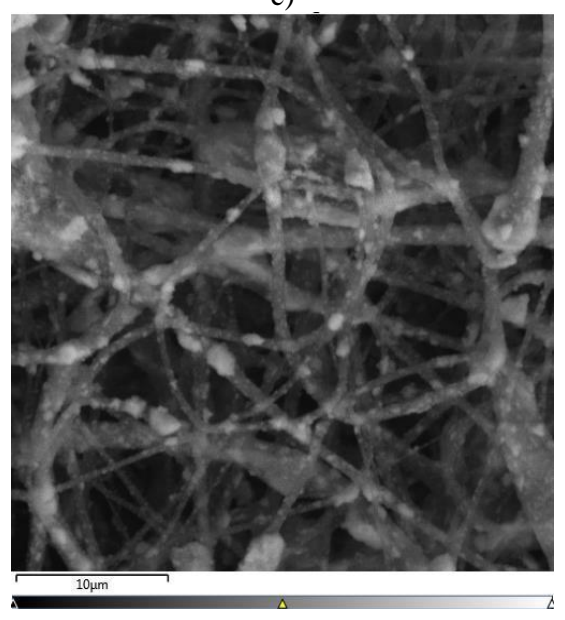

d) 


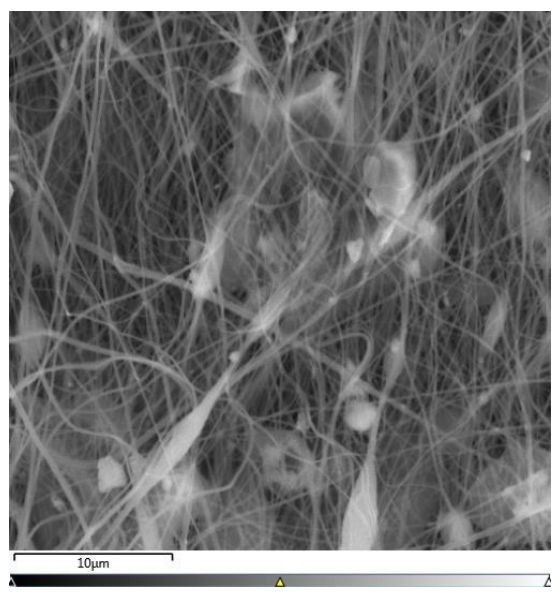

e)

Fig. 1. Scanning electron micrograph of a) PVDF nanofibers doped with TiO2; b) PVDF nanofibers doped with $\mathrm{ZnO}$; c) PVDF nanofibers doped with BT; d) PVDF nanofibers doped with BCZT; e) PVDF nanofibers doped with KNN.

Energy-dispersive X-ray analysis of PVDF modified with various dopants is presented in Figure 2. The overall pattern is that the constituent elements of respective dopants are clearly visible in the modified PVDF fibers.

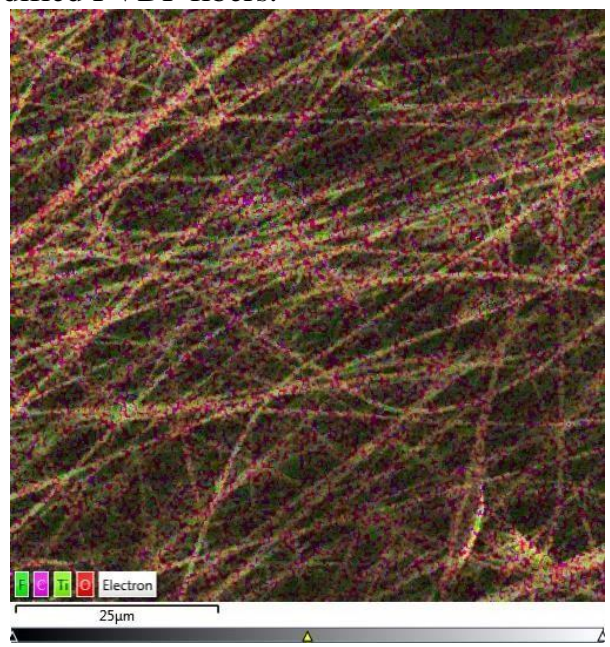

a) 


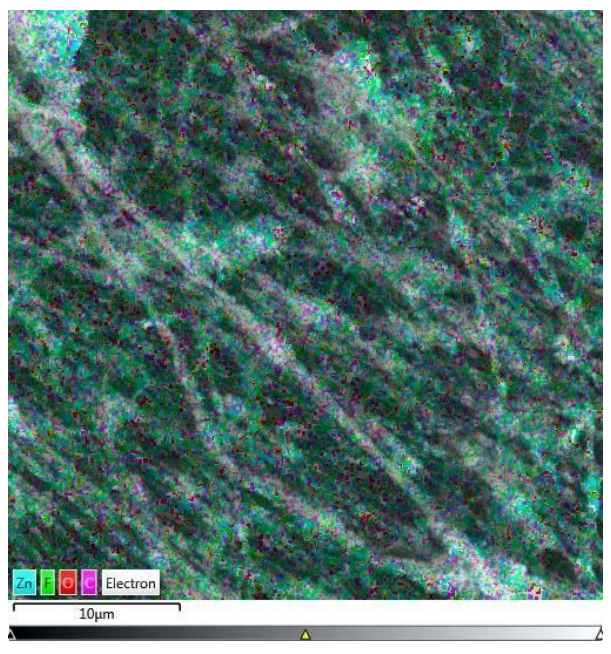

b)

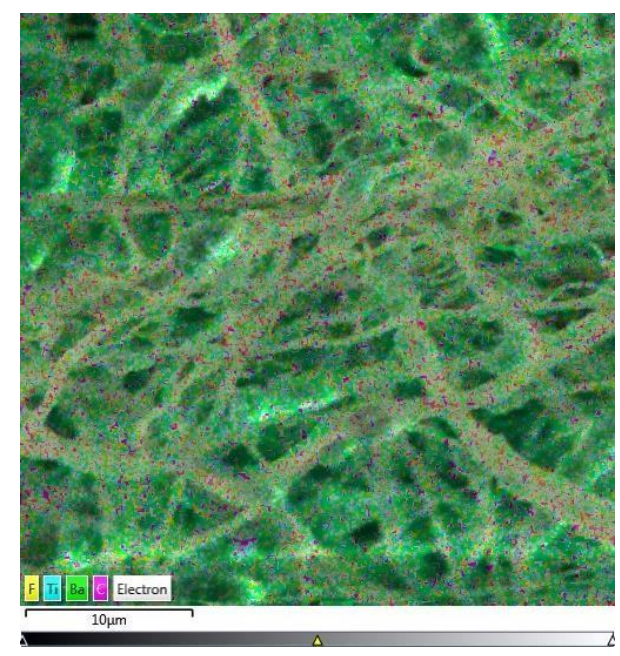

c) 


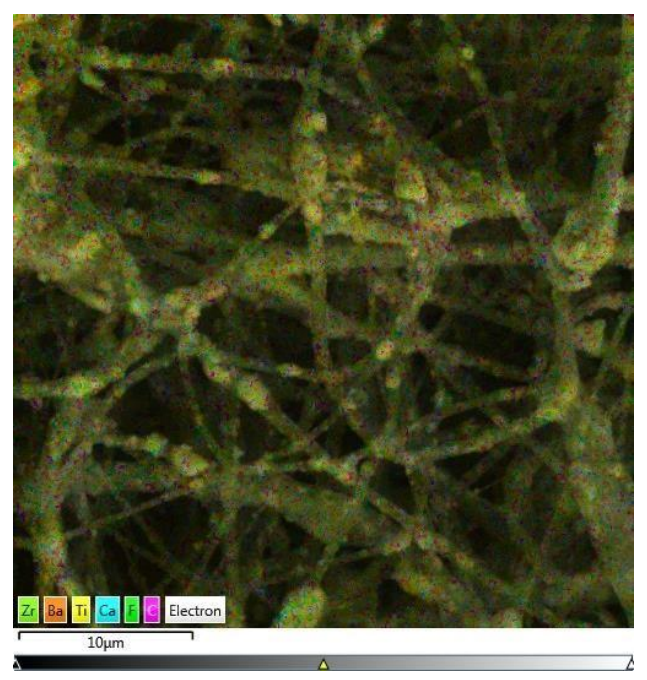

d)

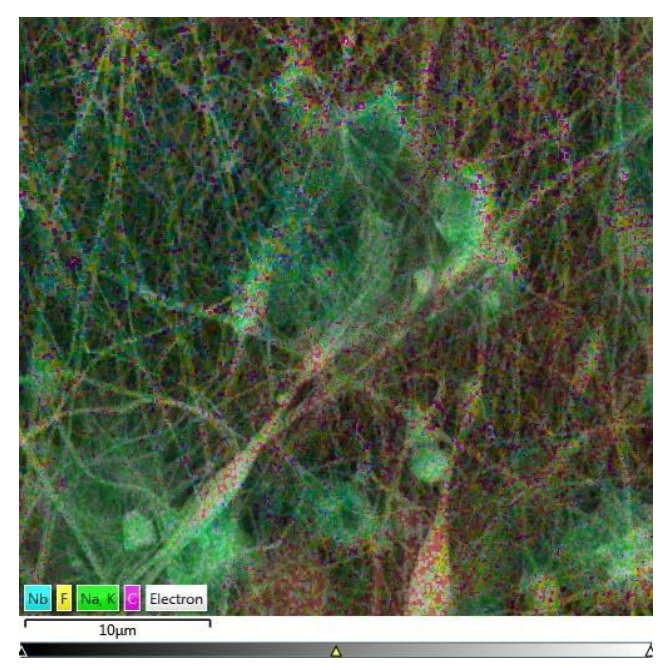

e)

Fig. 2. SEM-EDX micrographs of a) PVDF nanofibers doped with TiO2; b) PVDF nanofibers doped with $\mathrm{ZnO}$; c) PVDF nanofibers doped with BT; d) PVDF nanofibers doped with BCZT; e) PVDF nanofibers doped with KNN.

\subsection{X-ray photoelectron spectroscopy analysis}

The XPS analysis has been performed to gain insights into the chemical composition of PVDF doped with various compounds and support the results obtained by EDX analysis. The XPS wide spectrum for pure unmodified PVDF is given in Fig. 3. As we can observe, with the exception of very insignificant amount of oxygen (which might result from mild oxidation of the surface or from the microscopic amounts of moist from the atmosphere) there is no contamination in the PVDF structure which is an ideal case. 


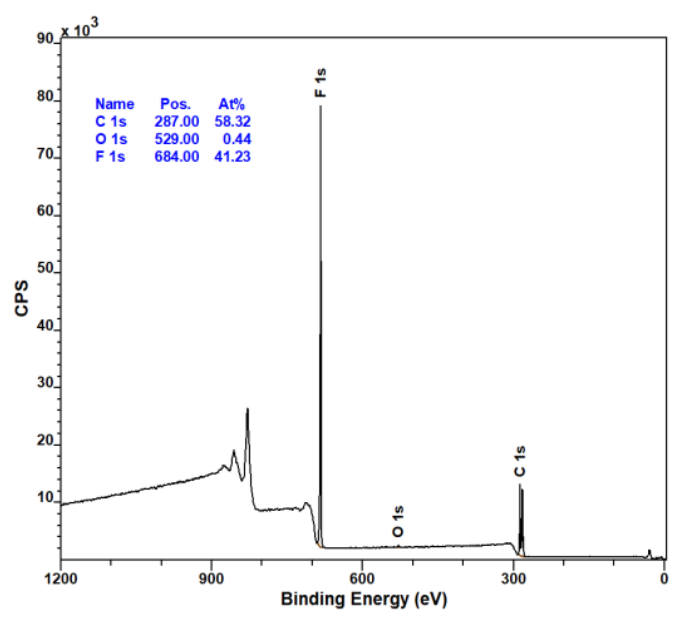

Fig. 3. XPS spectra of pure PVDF.

The XPS wide spectra for modified (doped) PVDF is given in Figure 4. Just as is the case with EDX, XPS Cleary indicates that doping procedure went successfully as we can cleary observe the emergence of the dopants constituent elements. Their concentration appears low due to overwhelming intensity of the main element of PVDF fibers, their presence, however, is undoubtable..

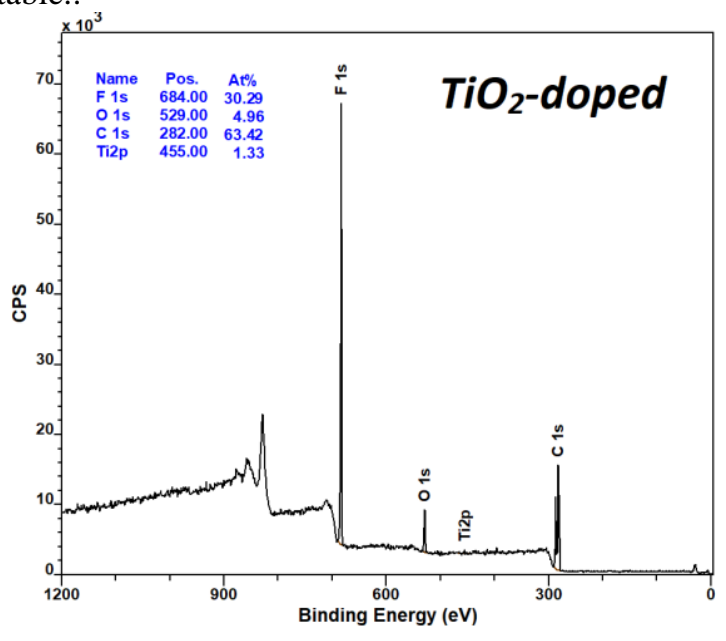

a) 


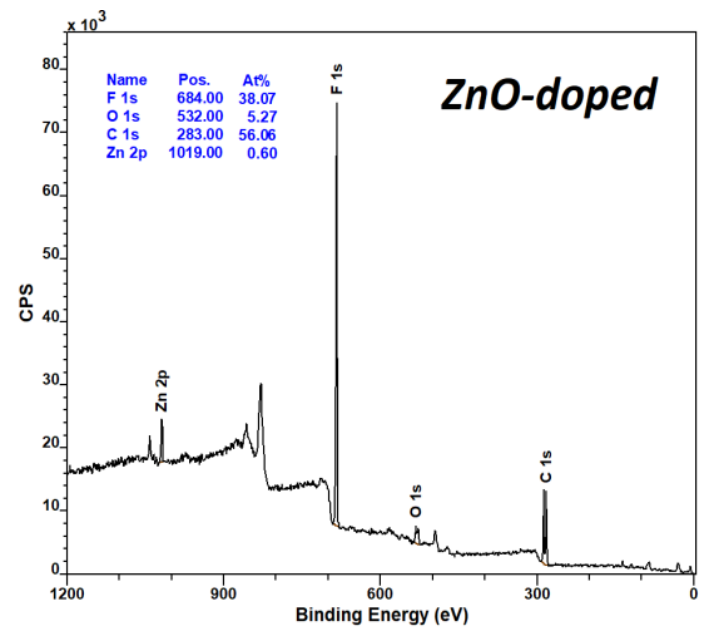

b)

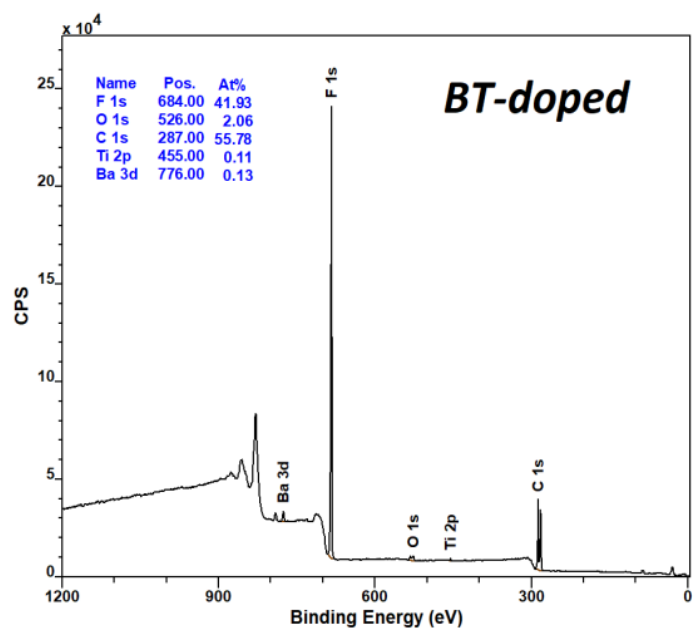

c)

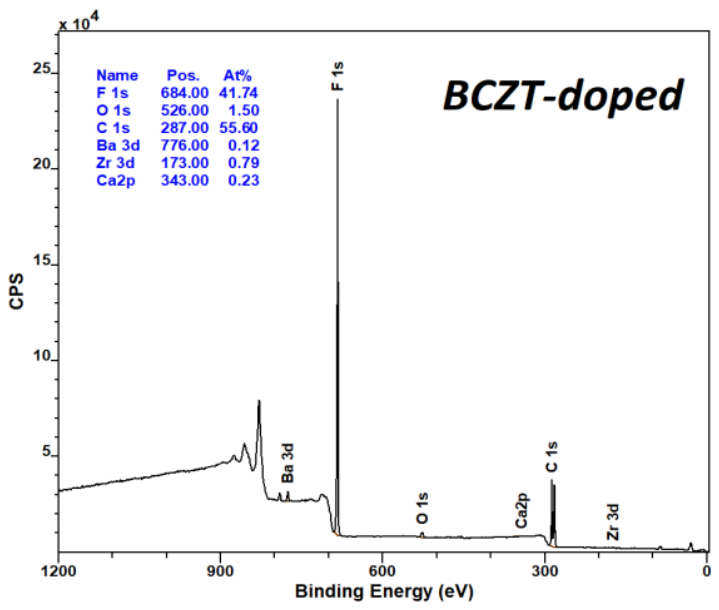

d) 
Fig. 4. XPS spectra for PVDF doped with: a) $\mathrm{TiO}_{2}$; b) $\mathrm{ZnO}$; c) $\mathrm{BT}$; d) $\mathrm{BCZT}$.

The doped fibers are highly hydrophobic (Figure 5). Angles were measured ten times and systematization is given in Table 1 .

Table 1. Measured angles and error.

\begin{tabular}{|c|c|c|}
\hline Materia & Avarage value $/{ }^{\circ}$ & ${ }^{\circ}$ Error \\
\hline PVDF-KNN & 133,8 & 4,7 \\
\hline PVDF-TiO2 & 130,8 & 6,6 \\
\hline PVDF-ZnO & 130,2 & 16,3 \\
\hline PVDF-BT & 138,2 & 2,7 \\
\hline PVDF-BCZT & 145,6 & 5,6 \\
\hline
\end{tabular}

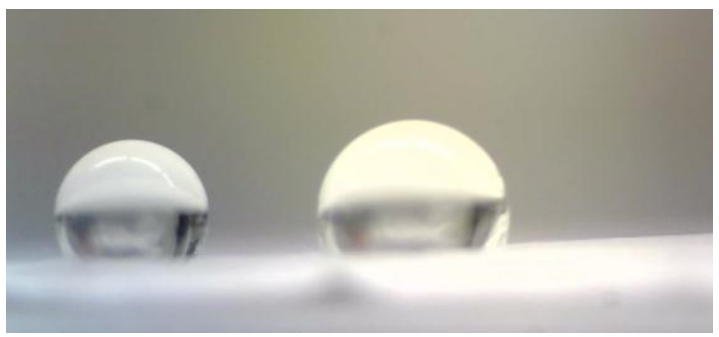

Fig. 5. Photo of water drops on the surface of the fibers.

\section{Conclusions}

Advances in the synthesis, modification and indeed the understanding of the piezoelectric polymers via the addition of piezoelectric ceramics to induce the piezoelectric $\beta$-phase in PVDF are providing new pathways for the development of multifunctional composites. This study describes polymers used to form those composites and gives a general overview of dopant materials used.

We can manipulate the properties of PVDF by doping it with various compounds. In the experimental section we demonstrated how using EDX analysis with can observe the constituent elements of doping compounds in the resulted polymers. XPS analysis has also been performed and their spectrum correlates with the EDX results.

Research described in this paper was financially supported by Internal Grant Agency of Brno University of Technology [Grant No. FEKT-S-20-6352] and Grant Agency of Czech Republic under project No. 19-17457S. A part of the work was carried out with the support of CEITEC Nano Research Infrastructure [grant ID LM2015041, MEYS CR, 2016-2019], CEITEC Brno University of Technology.

\section{References}

1. B. Amit, B. Susmita, Characterization of Biomaterials (Elsevier, 2013)

2. S. Anshuman, K.J. Karun, M. Pralay, K. Devendra, P. Om, Journal of Composites (2014) 
3. K. Buchtela, Handbook of Radioactivity Analysis ( $2^{\text {nd }}$ ed.) (Academic Press, 2004)

4. K. Částková, J. Kaštyl, D. Sobola, J. Petruš, E. Stastná, D. Riha, P. Tofel, Nanomaterials (Basel), 10(6),1221 (2020)

5. R.S. Dallaev, S. Stach, Ş. Ţălu, D. Sobola, A. Méndez-Albores, G.T. Córdova, L. Grmela, Silicon, 11(6), 2945 (2019)

6. D. Dallaeva, Ş. Ţălu, S. Stach, P. Škarvada, P. Tománek, L. Grmela, Appl. Surf. Sci., 312, 81 (2014)

7. Focused Ion Beam/Scanning Electron Microscope TESCAN LYRA3 (LYRA). CEITEC Nano Research Infrastructure. Brno, http://nano.ceitec.cz (2020)

8. J.T. Fourie, Gold Bull, 15, 2 (1982)

9. A. Frattini, A. Di Loreto, O. de Sanctis, B. Edgardo, Materials Science, 1 (2012)

10. R.M. Geoffrey, Electrospinning: Principles, Practice and Possibilities (Cambridge: Royal Society of Chemistry, 2015)

11. E. Gorokhova, P. Rodnyi, E. Lokshin, K. Lott, G. Kunshina, K. Chernenko, G. Ananieva, S. Eron'ko, I. Khodyuk, O. Gromov, E. Oreschenko, J. Opt. Technol., 78, 753 (2011)

12. S.A. Haddadi, S. Ghaderi, M. Amini, S.A. Ahmad-Ramazani, Mater. Today Proc., 5(7), 15710 (2018)

13. B.S. Har, A.B. Kumar, Handbook of Natural Dyes and Pigments (Woodhead, 2014)

14. G. Höflinger, Leica Micro-systems (2013)

15. P. Huisheng, S. Xuemei, W. Wei, F. Xin, Academic Press, 5, 151 (2017)

16. S. Javed, M. Islam, M. Mujahid, Ceram Int, 45, 2676 (2019)

17. W. Jiagang, Advances in lead-free piezoelectric materials (Springer Singapore Pte. Limited, 2018)

18. P. Kaspar, D. Sobola, K. Částková, A. Knápek, D. Burda, F. Orudzhev, R. Dallaev, P. Tofel, T. Trčka, L. Grmela, Z. Hadaš, Polymers (Basel), 12, 1 (2020)

19. O. Kazushige, Piezoelectric Properties and Microstructure of (K,Na) $\mathrm{NbO}_{3}-\mathrm{KTiNbO}_{5}$ Composite lead-free piezoelectric ceramic, piezoelectric materials (Toshio Ogawa, 2016)

20. A. Knápek, M. Horaček, J. Chlumská, T. Kuparowitz, D. Sobola, J. Šikula, Metrology and measurement systems, 25(3), 451 (2018)

21. Y. Li, X. Ge, L. Wang, L. Wang, W. Liu, H. Li, R. Kwok, S. Chin, Curr. Nanosci., 9, 679 (2013)

22. Y. Li, C. Liao, S.C. Tjong, Nanomaterials, 9, 952 (2019)

23. J.-F. Li, K. Wang, F.-Y. Zhu, L.-Q. Cheng, F.-Z. Yao, J. Am. Ceram. Soc., 96(12), 3677 (2013)

24. J.Y. Lim, S. Kim, Y. Seo, AIP Conf. Proc., 1664, 070006 (2015)

25. C. Liu, J. Shen, C.Z. Liao, K.W.K. Yeung, S.C. Tjong, Express Polym. Lett., 12, 365 (2018)

26. D.C. Look, Journal of Elec Materi., 35, 1299 (2006)

27. E. Luyk, Thermo Fisher Scientific (2019)

28. P. Martins, A.C. Lopes, S. Lanceros-Méndez, Prog. Polym. Sci., 39, 683 (2014)

29. F.M. Mwema, E.T. Akinlabi, O.P. Oladijo, O.S. Fatoba, S.A. Akinlabi, Ş. Țălu, Modern Manufacturing Processes, 1(1-2), 13 (2020) 
30. Ü. Özgür, Y. Alivov, C. Liu, A. Teke, M. Reshchikov, S. Dogan, V. Avrutin, S-J. Cho, H. Morkoç, Journal of Applied Physics, 98, 041301 (2005)

31. P. Parjansri, U. Intatha, K. Pengpat, S. Eitssayeam, Appl. Phys. A, 125, 421 (2019)

32. R. Patel, C. Prakash, P. Kumar, AIP Conference Proceedings, 1372, 116 (2011)

33. S. Ramazanov, Ş. Ţălu, D. Sobola, S. Stach, G. Ramazanov, Superlattice Microst, 86, 395 (2015)

34. S. Ramazanov, D. Sobola, F. Orudzhev, A. Knápek, J. Polčák, M. Potoček, P. Kaspar, R. Dallaev, Nanomaterials, 10, 1990 (2020)

35. D. Sobola, P. Kaspar, J. Oulehla, Ş. Ţălu, N. Papež, Mater Sci-Poland (2020)

36. S. Stach, D. Dallaeva, Ş. Ţălu, P. Kaspar, P. Tománek, S. Giovanzana, L. Grmela, Mater Sci-Poland, 33(1), 175 (2015)

37. B.D. Stojanovic, V.R. Mastelaro, C.O. Paiva Santos, J.A. Varela, Science of Sintering, 36, 179 (2004)

38. Ş. Țălu, Micro and nanoscale characterization of three dimensional surfaces. Basics and applications (Napoca Star Publishing House, Cluj-Napoca, Romania, 2015)

39. Ş. Ţălu, D. Sobola, N. Papež, R. Dallaev, P. Sedlák, Education and Human Science, 202 (2018)

40. K. Uchino, Ferroelectric devices (New York, Marcel Dekker, 2000)

41. H. You, Z. Wu, Y. Jia, X. Xu, Y. Xia, Z. Han, Y. Wang, Chemosphere, 183, 528 (2017)

42. G. Wallace, P. Teasdale, G. Spinks, L.A.P. Kane-Maguire, Conductive Electroactive Polymers: Intelligent Polymer Systems ( $3^{\text {rd }}$ edition, CRC Press, 2008) 